\title{
Workflow for coupled daylight and energy simulations
}

\author{
Tobias Skov Pedersen ${ }^{1}$ and Helle Foldbjerg Rasmussen ${ }^{1}{ }^{*}$ \\ ${ }^{1}$ MicroShade A/S, Gregersensvej 1F, 2630 Taastrup, Denmark
}

\begin{abstract}
The objective of this paper is to present a methodology with corresponding case study on how to perform coupled daylight and energy simulations with high accuracy. It is coupled in the sense that the annual daylight and energy simulations rely on the same assumptions. The workflow is developed with the intended use of evaluating performance of solar shading systems, but the approach can also be applied to other areas of interest within building simulations. Since the correct modelling of fenestrations and solar shading systems is a crucial part in the integrity of any building simulation.
\end{abstract}

\section{Introduction}

As a manufacturer of solar shading we are frequently advising industry professionals, such as architects and engineers, on how to accurately model the performance of different solar shading systems. In general, there is goodwill towards best practice methods, but oftentimes they get neglected when deadlines are approaching, since there is currently no easy-to-use, coupled and time efficient approach to model both energy and daylight performance of solar shading systems with high accuracy.

Hence, there is a tendency to fall back to the lowest common denominator of approaches that are quick, simple and in compliance with building regulations. E.g. in the Danish Building Regulation [1], the daylight availability can be documented with window to floor ratio (WFR) failing to account for the real time effects of solar shading on the daylight environment, while on the same building any type of solar shading can be used to document thermal indoor comfort. However, these approaches fail to accurately model solar shading performance, leading to decreased thermal comfort and/or daylight accessibility.

In order to remove these inaccuracies, a coupling of the daylight and energy simulations is highly recommended.

\section{Suggested Workflow}

The idea behind coupling daylight and energy simulations is to make sure they rely on the same assumptions.

The important assumptions to align are the following:

- Geometry definition

- Weather data
- Control strategy for dynamic shading systems

- Angular optical properties of the fenestration and solar shading system (in all states)

Dynamic shading systems are systems that changes state based on a control strategy. Examples are: Operable venetian blinds, operable screens and thermochromic windows. A dynamic shading system will have two or more states, for instance venetian blinds lowered and raised. In contrast passive shading systems include; MicroShade, solar control glazing and any non-operable part of the facade intended for shading. Passive shading systems only have one state.

It seems trivial that the simulations must rely on the same weather data and geometry definition. However, since the daylight and energy simulations often are performed in separate software, by separate people, sometimes even in separate departments or companies, accordance is not guaranteed. E.g. when geometry is changed updates to the model is only implemented in one of the two places, or weather data from different sources are used for the two simulations. The impact of using different weather data has been described in [2] and shows that significant differences can occur by using different weather data.

The way control strategies are defined often differs between daylight and energy simulation tools and therefore this parameter is often not aligned even though the control of dynamic shadings has a mayor impact on the resulting daylight accessibility and thermal comfort. In the result section of this paper it is shown how different control strategies can change the results significantly.

Angular optical properties are another assumption that has a high impact on the result of energy and daylight simulations. The angular optical properties are the changing transmittance, reflectivity and absorptance coefficient relative to the position of the sun for a 
given solar shading state. To account for angle dependency the BSDF format can be used.

\subsection{The BSDF format}

The Bidirectional Scattering Distribution Function (BSDF) is an accurate and efficient format for portraying angular optical properties of windows and shading systems. The format describes both specular properties and scattering properties as seen in Fig. 1. The BSDF format is well integrated into validated and open source calculation engines such as Radiance and EnergyPlus.

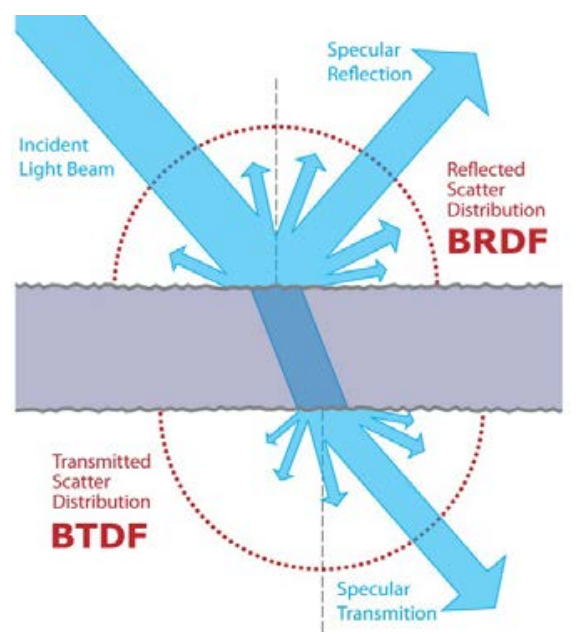

Fig. 1. Illustration of the scattering and specular information captured in the BSDF format. [3]

BSDF files can be created using LBNL WINDOW [4]. The software uses state of the art methods, combined with empirical spectral data from the International Glazing Database (IGDB) to generate the BSDF files as documented in [5]. Both the Insulated Glass Unit (IGU) and the solar shading device must be considered, when generating the BSDF files for daylight and energy simulations. In this way the BSDF file will represent the entire fenestration and shading system. Furthermore, BSDF files allow for using the Five-Phase Method [6] for daylight simulation for shorter simulation time.

\subsection{Simulation engines}

Any simulation is only as accurate as the underlying engine. Hence it is sought to find the engines with the best validation and ability to accurately model solar shading performance. To meet this accuracy requirement the engines should be able to use BSDF files.

Radiance [7] is the industry standard for daylight simulations and Climate Based Daylight Modelling (CMBD) has been validated [8]. It is possible to use BSDF files. Radiance was therefore chosen as the daylight simulation engine.

EnergyPlus [9] is a whole building energy simulation engine. EnergyPlus excels by being well validated [10], easy to get started with and compliant with the BSDF format. Therefore, EnergyPlus was chosen as the energy and indoor climate simulation engine.

\subsection{Graphical User Interface (GUI)}

There are many ways to apply Radiance and EnergyPlus. The expert level usage of Radiance is executing the program directly from the command prompt. Similarly, for EnergyPlus writing the input text files and executing the program without the use of a GUI. However, this approach requires a lot of in-depth knowledge about both engines in terms of syntax and underlying algorithms and are not well suited for someone who wishes to try out the workflow for the first time.

Therefore, it is suggested to access both Radiance and EnergyPlus through a GUI. There are many GUIs available for both Radiance and EnergyPlus. Unfortunately, there is a tendency, that the more flexible they are and the greater the opportunity to do accurate modelling is, the steeper the learning curve.

As a compromise between flexibility, accuracy and learning effort, Ladybug Tools is suggested as a GUI for using this workflow. Ladybug Tools are well alligned with ideas behind the workflow in several ways:

- Both EnergyPlus and Radiance are accessible from within the same GUI, allowing one to store geometry definitions in only one place.

- The weather file only needs to be loaded once to the GUI and can be used for both energy and daylight simulation.

- The same shading schedule for both energy and daylight simulation for dynamic shading systems can be used.

- BSDF files can be used for both EnergyPlus and Radiance through Ladybug Tools.

Moreover, Ladybug Tools provides the most comprehensive visualization tools for PMV and PPD metrics to quantify thermal indoor comfort [11].

\section{Case Study}

The case study shows a possible application for the coupled daylight and energy workflow. The motivation behind the case study is to gain a thorough understanding of the impact when applying solar shading to many different situations. To gain this understanding the study will be parametric varying solar shading systems, geometry, orientation, WFR and location. Due to its parametric nature the workflow relies mostly on scripting using Python, to automate the simulation process.

\subsection{Shading systems}

Ten different solar shading systems was used in the case study and can be seen in Table 1 . All the shading systems are configured to a three layer 6-14-6-14-6 mm IGU, with $90 \%$ argon in the cavities.

The angle dependency of the systems can be seen in Fig. 2. Fig. 3 displays pictures of some of the selected 
systems, where qualities like colour rendering can be seen.

Table 1. Fenestration and shading systems used in the case study

\begin{tabular}{|l|l|l|}
\hline $\begin{array}{l}\text { Fenestration } \\
\text { and shading } \\
\text { systems }\end{array}$ & Description & Abbreviation \\
\hline $\begin{array}{l}\text { Low energy } \\
\text { glazing }\end{array}$ & Low emission glazing & LowE \\
\hline \multirow{4}{*}{$\begin{array}{l}\text { Solar control } \\
\text { glazing }\end{array}$} & $\begin{array}{l}\text { Cool-Lite Extreme } \\
50 / 22\end{array}$ & CLX50/22 \\
\cline { 2 - 3 } & $\begin{array}{l}\text { Cool-Lite Extreme } \\
60 / 28\end{array}$ & CLX60/28 \\
\cline { 2 - 3 } & Cool-Lite SKN165 & SKN165 \\
\hline \multirow{2}{*}{ Microlamellas } & MicroShade ${ }^{\mathbb{B}}$ MS-A & MS-A \\
\cline { 2 - 3 } Screen fabric & $\begin{array}{l}\text { MicroShade }{ }^{\mathbb{B}} \text { MS-D } \\
\text { normal of 5 \% } \%\end{array}$ & MS-D \\
\cline { 2 - 3 } & $\begin{array}{l}\text { Solar transmittance } \\
\text { at normal of } 14 \%\end{array}$ & Screen_0_05 \\
\hline \multirow{2}{*}{$\begin{array}{l}\text { Venetian } \\
\text { blinds }\end{array}$} & $\begin{array}{l}\text { Lamellas tilted 30 } \\
\text { degrees }\end{array}$ & Blinds_30_14 \\
\cline { 2 - 3 } & $\begin{array}{l}\text { Lamellas tilted 45 } \\
\text { degrees }\end{array}$ & Blinds_45 \\
\hline
\end{tabular}
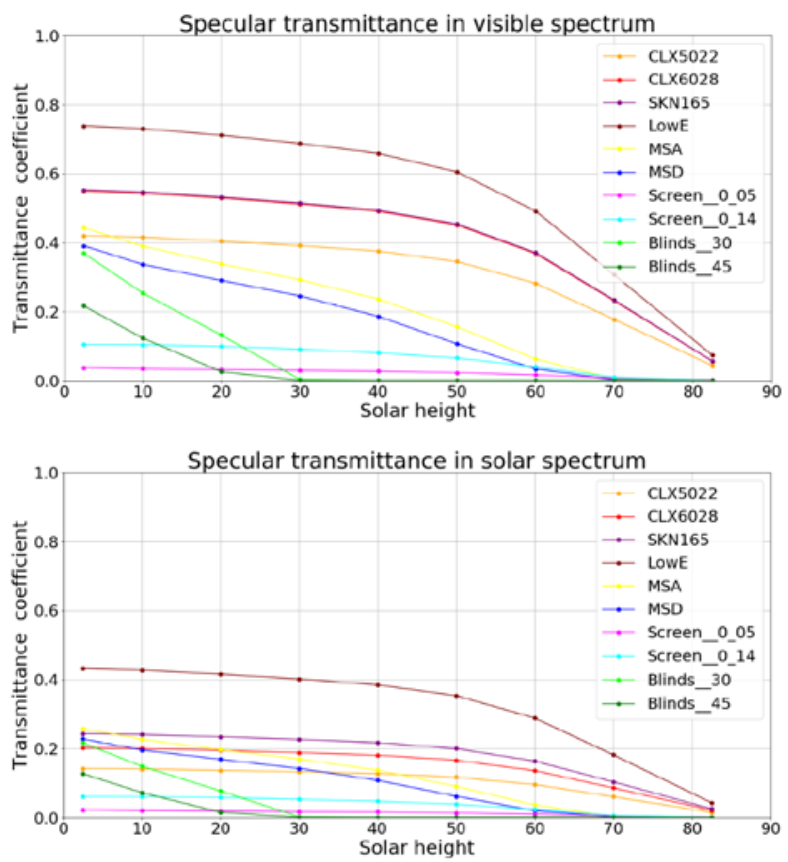

Fig. 2. Specular transmittance for typical solar shading systems from BSDF files generated with WINDOW. The transmittance coefficient is plotted as a function of solar height with azimuth constantly perpendicular to the facade.

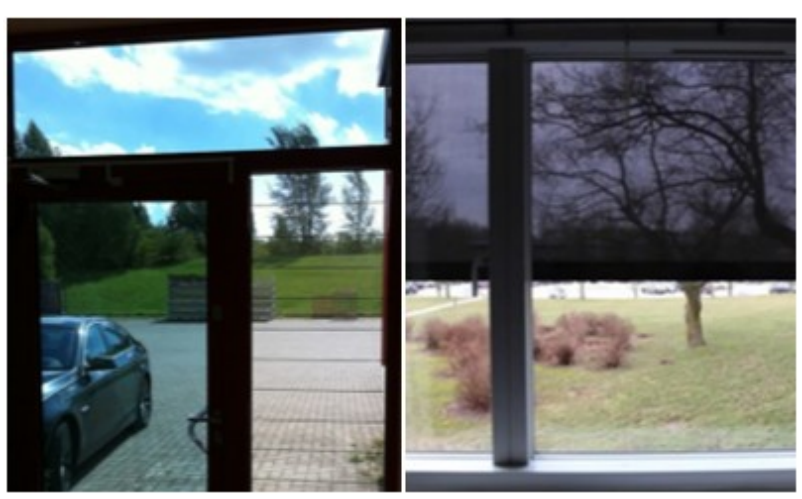

Fig. 3. Examples of solar shading systems used in the case study. Left picture, top: Standard LowE glazing. Left picture, right: MicroShade ${ }^{\circledR}$. Left picture, left: Solar control glazing. Right picture: Screen fabric

For the four dynamic shadings systems the activation threshold was varied in the case study - ranging from 50 $\mathrm{W} / \mathrm{m}^{2}$ to $350 \mathrm{~W} / \mathrm{m}^{2}$ solar irradiation on the facade by increments of $50 \mathrm{~W} / \mathrm{m}^{2}$.

\subsection{Office geometry}

For the case study a generic large office and small office was modelled. Fig. 4 display the two models.
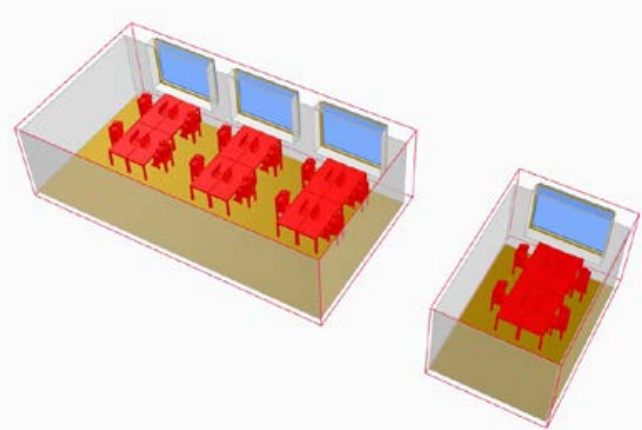

Fig. 4. Generic large and small office. Red outlines are the surfaces used for input in EnergyPlus. Shaded surfaces are used for input in Radiance.

When modelling geometry, it is important to be mindful of which faces of the constructions the simulation engines needs as input. In case of Radiance it uses the internal faces of the construction, when simulating daylight levels inside the room. EnergyPlus takes outside face of external walls and centreline face of internal walls for the most accurate modelling of heat transfer surfaces and amount of thermal mass, as stated in [12]. Failing to assign the appropriate faces to the given engines will decrease accuracy.

Another important aspect regarding geometry modelling, especially for CMBD, is window frame and sill detailing. As seen in Fig. 5 both sill and frame (also divider if present) should be considered. 


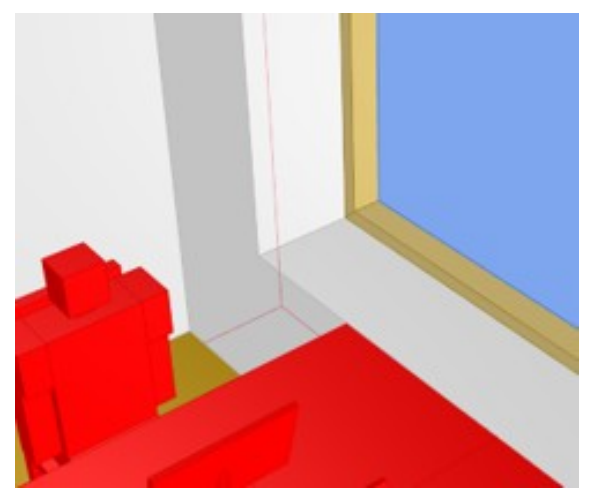

Fig. 5. Window detailing used for case study.

The window to floor ratio (WFR) was varied in the case study - ranging from $10 \%$ to $40 \%$ by increments of $5 \%$. The different WFR used in the case study can be seen in Fig. 6.
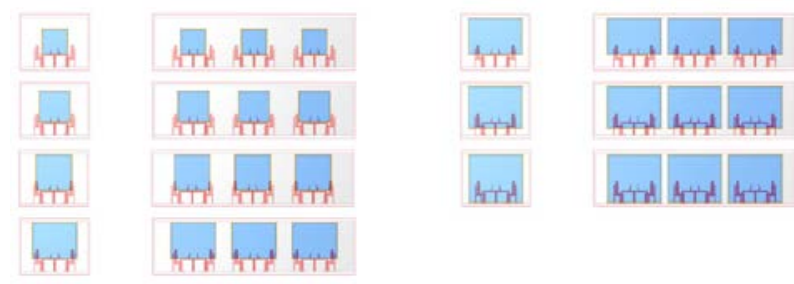

Fig. 6. WFR used for case study.

\subsection{Location and orientation}

To understand the impact of sun positions and locations a variety of locations was selected for the case study. Mainly locations in Europe was considered ranging from Trondheim in North to Madrid in South, but also Sydney was chosen to represent the southern hemisphere. The selected locations can be seen in Figure 7.

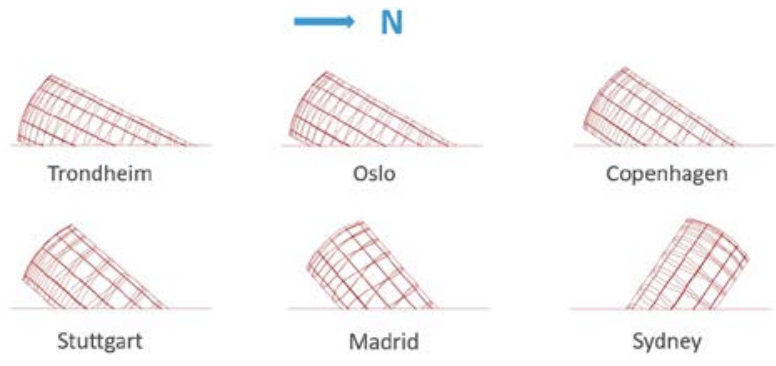

Fig. 7. Annual sun positions and analemmas for location used in case study.

For each scenario 16 different orientations was considered. The orientations can be seen in Fig. 8 .

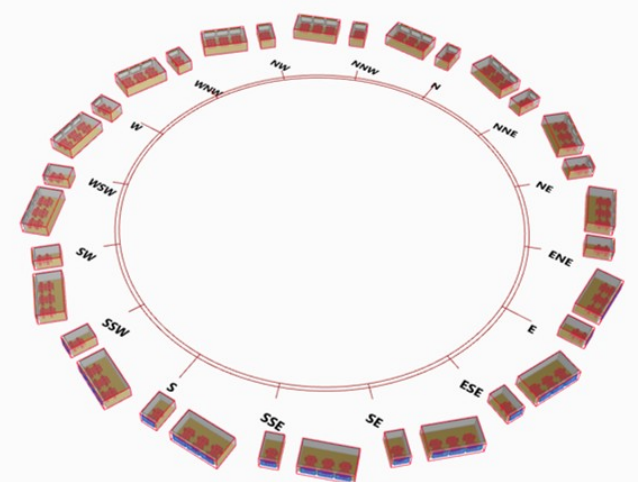

Fig. 8. Orientations used for case study

\subsection{Output and usage}

Depending on the intended use of the workflow it is possible to get the relevant data output. For instance, it is possible to get the following outputs;

- Annual temperature inside the offices, e.g. number of hours above $26^{\circ} \mathrm{C}$ according to EN15251 [13]

- Annual Energy Usage Intensity (EUI) for cooling and heating

- Peak energy usage for cooling and heating

- PMV and PPD indoor comfort maps

- Temperature distribution through the fenestration system

- Annual illuminance levels inside the offices, e.g. percentage of area above 300 lux for more than $50 \%$ of the daylight hours according to EN17037 [14]

- Quantity of view out for dynamic shadings systems

- Colour rendering

This case study was used to evaluate the performance of different solar shading systems in terms of indoor climate, daylight and view out.

\section{Results}

Since more than 20,000 scenarios was simulated it is not possible to show all the results in this paper. Therefore, it was chosen to pick out a south façade in Stuttgart, for the large office with a WFR of $40 \%$.

It was chosen to evaluate the different shading solutions based on three criteria; thermal indoor climate, daylight and weighted view out. A detailed description of the criteria is given in [15].

The thermal indoor climate is evaluated according to EN15251, where an acceptable indoor climate requires a maximum of 100 hours above $26^{\circ} \mathrm{C}$ during occupancy hours.

The daylight availability is evaluated according to EN17037, where it is required that, minimum $50 \%$ of the area should receive more than 300 lux in more than $50 \%$ of the daylight hours.

The weighted view out is the activation time weighted with the view out class from EN14501[16]. The weighting factors are defined in [17]. The static shadings 
are "activated" $100 \%$ of the time. According to [17] it is recommended to have a minimum of $80 \%$ weighted view out.

The view out class for the shadings in accordance to EN14501 are showed in Table 2.

Table 2. View out class for the shading systems.

\begin{tabular}{|l|l|c|}
\hline \multicolumn{2}{|l|}{$\begin{array}{l}\text { Fenestration and shading } \\
\text { systems }\end{array}$} & $\begin{array}{c}\text { View out } \\
\text { class }\end{array}$ \\
\hline \multirow{2}{*}{$\begin{array}{l}\text { Solar control } \\
\text { glazing }\end{array}$} & CLX50/22 & 4 \\
\cline { 2 - 3 } & CLX60/28 & 4 \\
\cline { 2 - 3 } & SKN165 & 4 \\
\hline \multirow{2}{*}{ Microlamellas } & MS-A & 4 \\
\cline { 2 - 3 } & MS-D & 4 \\
\hline \multirow{2}{*}{ Screen fabric } & Screen_0_05 & 2 \\
\cline { 2 - 3 } & Screen_0_14 & 3 \\
\hline \multirow{2}{*}{$\begin{array}{l}\text { Venetian } \\
\text { blinds }\end{array}$} & Blinds_30 & 3 \\
\cline { 2 - 3 } & Blinds_45 & 3 \\
\hline
\end{tabular}

In Fig. 9 the thermal performance for the dynamic shading systems are shown. The EN15251 criteria on thermal indoor climate is fulfilled at different thresholds for the different shadings. For the blinds at $30^{\circ}$ slat angle it is obtained at a trigger value of $50 \mathrm{~W} / \mathrm{m}^{2}$, while it is $150 \mathrm{~W} / \mathrm{m}^{2}$ for the slats at $45^{\circ}$. For the screen with a transmittance of $5 \%$ it is obtained at $250 \mathrm{~W} / \mathrm{m}^{2}$, while for the screen with $14 \%$ transmittance it is obtained at 150 $\mathrm{W} / \mathrm{m}^{2}$. Hence, the activation threshold is highly influencing the thermal indoor climate results for each dynamic shading type.

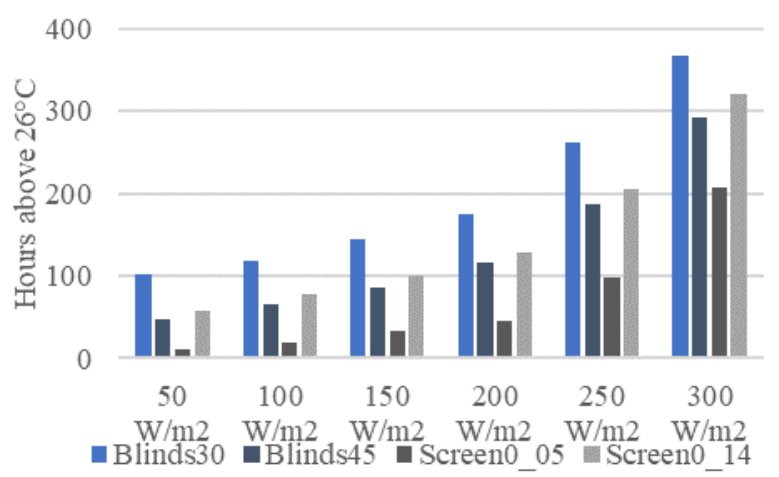

Fig. 9. Number of hours above $26^{\circ} \mathrm{C}$ for the dynamic shading systems (Stuttgart, large office, $40 \%$ WFR, South).

In Fig. 10 the thermal indoor climate, daylight and weighted view out performance for each of the shading types are shown. Only the dynamic shading with a maximum of 100 hours above $26^{\circ} \mathrm{C}$ is shown.

The thermal indoor climate criteria from EN15251 is meet by all shading solutions except CLX60/28 and SKN165. The corresponding daylight criteria in accordance to EN 17037 is meet by all shading solutions except Screen14\%@150W/m². However, it is worth noticing that CLX50/22 has a color rendering of only 82, while the rest of the shading solutions has color renderings above 90 .

The weighted view out criteria is only meet by the static shading solutions. The dynamic shadings are activated between $40-81 \%$ of the occupancy hours resulting in weighted view out of $8-32 \%$.

Thus, it is only CLX50/22 and MicroShade ${ }^{\circledR}$ who fulfill all three performance criteria.

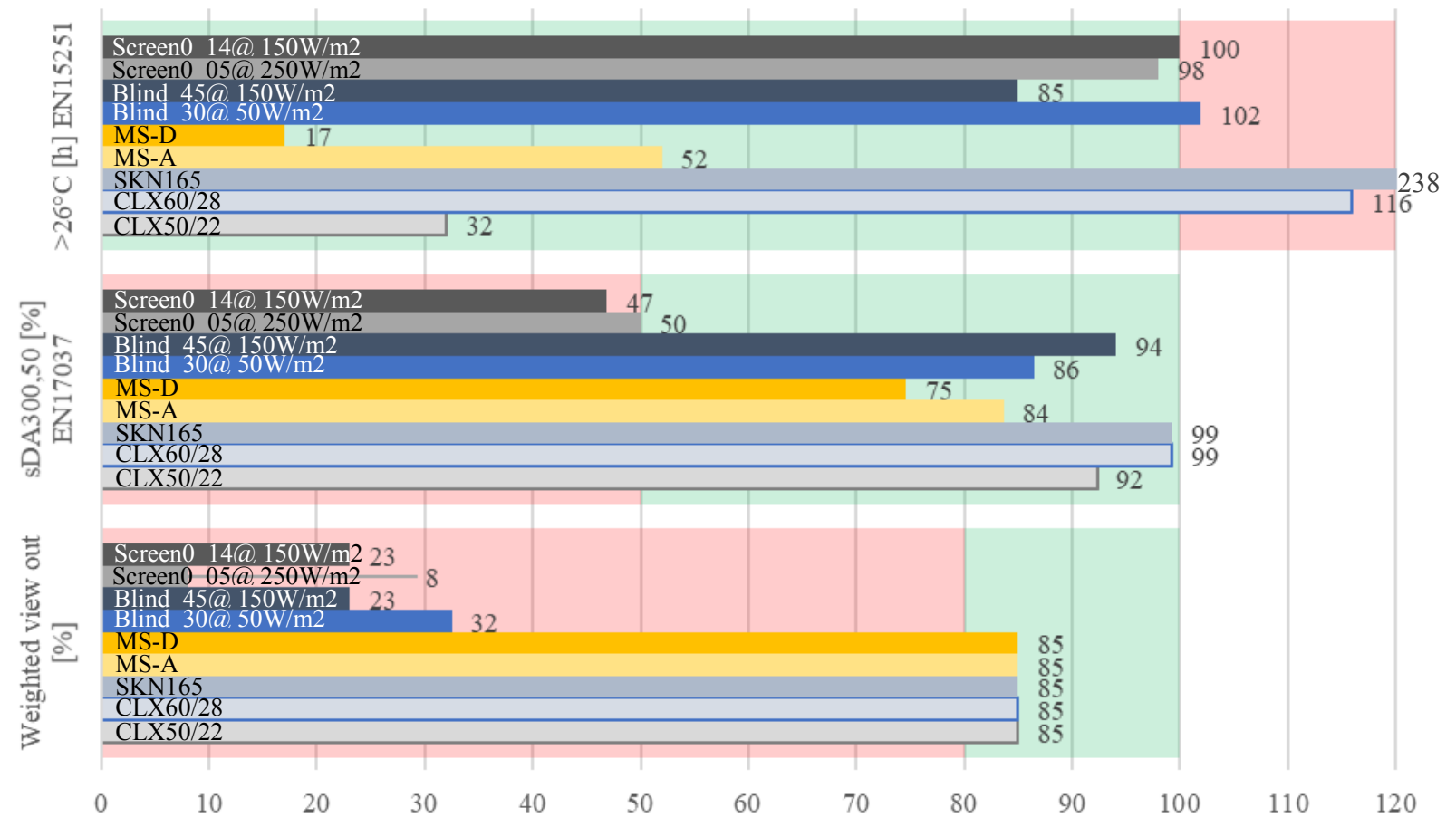

Fig. 10. Number of hours above $26^{\circ} \mathrm{C}$, spatial daylight autonomy and weighted view out for all shading systems (Stuttgart, large office, $40 \%$ WFR, South). 


\section{Conclusion}

To optimize building design for high performance buildings it is important to analyse the complex interaction between daylight, indoor climate/energy and view out based on the same assumptions and with high accuracy. An approach to how this can be done has been showed with the described workflow and case study. Hopefully, this can serve as an inspiration for consultants. Moreover, we need software developers to help make workflows like this easier to use for consultants, so that the best practice method becomes default and easy to use.

Furthermore, it would be desirable if the fenestration and shading description could be standardized for both energy/indoor climate and daylight simulations. The BSDF format can be used for thermal calculations and annual illuminance simulations, however, when a more detailed analysis of specific point in time or glare analysis is required, the resolution of the BSDF format has proved to be to course for some shading systems [18]. Therefore, the BSDF format needs to come with recommendations for resolution for different types of glazing and shading systems. With this recommendation the BSDF format could serve as a new standardized description of fenestration and shading systems. This work is already ongoing [18].

\section{References}

[1] BR18 Danish Building Regulation (2018)

[2] S. Erba, F. Causone, and R. Armani. The effect of weather datasets on building energy simulation outputs. The Energy Procedia 134, p. 545-554. (2017)

[3] https://commons.wikimedia.org

[4] LBNL Window

https://windows.lbl.gov/software/window

[5] C. Curcija, S. Vidanovic, R. Hart, J. Jonsson, R. Mitchell, (Windows, and Envelope Materi- als Group). WINDOW Technical Documentation.

Lawrence Berkeley National Laboratory, 2018.

[6] S. Subramaniam. Daylighting Simulations with Radiance using Matrix-based Methods. Lawrence Berke- ley National Laboratory, 2017.

[7] https://www.radiance-online.org/

[8] J. Mardaljevic. Daylight Simulation: Validation, Sky models and Daylight Coefficients. PhD thesis, De

Montfort University, Leicester, UK, 2000.

[9] https://energyplus.net/

[10] https://energyplus.net/testing

[11] C. W. Mackey. PAN CLIMATIC HUMANS -

Shaping Thermal Habits in an Unconditioned Society.

Massachusetts Institute of Technology, 2015.

[12] EnergyPlus Documentation Tips \& Tricks for Using

EnergyPlus - Insider secrets to Using EnergyPlus. U.S.

Department of Energy, 2018.

[13] EN 15251 Indoor environmental input parameters for design and assessment of energy performance of

buildings-addressing indoor air quality, thermal

environment, lighting and acoustics. (2007)
[14] EN 17037 Daylight of Buildings (2018)

[15] H.F. Rasmussen et al. An industry perspective on

building simulations with solar shading. Clima2019

procedings. (2019)

[16] EN14501 Blinds and shutters - Thermal and Visual Comfort-Performance characteristics and

classification. (2005)

[17] M. Vorre et al. Industry-guideline for indoor climate simulations (2017), SBI

[18] https://www.radiance-

online.org/community/workshops/2018-

loughborough/presentations/03-HighResBSDFs.pdf 